http://dx.doi.org/10.12795/PH.1990.v05.i01.24

\title{
«EI siglo de las luces»: una sonata de Alejo Carpentier
}

\author{
José Antonio Sánchez Zamorano
}

\section{Introducción. Novela, música y mito}

La crítica, en repetidas ocasiones, ha puesto de manifiesto el hecho de que Alejo Carpentier traslade a su narrativa ordenaciones y esquemas relacionados, en principio, con el ámbito de la composición musical. Ya en su primera novela, Ecué-Yamba-O (1.933), se rastrean algunas trasposiciones: la materia narrativa aparece distribuida siguiendo ciertas simetrías, tendentes a cerrar la estructura -lo que constituye uno de los principios básicos del arte musical-, y se usa la técnica de la recurrencia temática -en música, variaciones sobre un tema- ${ }^{1}$.

Sin entrar en arbitrarias discusiones sobre sus nombres, se puede llegar a convenir que la casi totalidad de las obras posteriores de Carpentier se adapta a estructuras de tipo musical. Así, se ha concebido El reino de este mundo (1949) como una suite de ballet. Los pasos perdidos (1953) se ha puesto en relación con una cantata. El acoso (1956) puede considerarse como sonata -o como sinfonía-. El siglo de las luces (1962) se aproximaría al poema sinfónico. El recurso del método (1974) y Concierto barroco (1974) se ajustarían, respectivamente, a las cualidades de la ópera bufa y del «concerto grosso»². Análogas conclusiones parecen aceptables con respecto a los relatos.

El mismo Carpentier ha hecho alusión, muchas veces, a la íntima relación establecida entre sus múltiples y, en apariencia, diversas «tareas»: literatura, música,

\footnotetext{
${ }^{1}$ Alexis Márquez Rodríguez, La obra narrativa de Alejo Carpentier, Univ. Central de Venezuela, 1970, p. 23.

${ }^{2}$ Leonardo Acosta, Música y época en la novela de Alejo Carpentier, Editorial Letras Cubanas, La Habana, 1981, p. 24.
} 
arquitectura, historiografía... publicidad. En un artículo titulado «Novela y música» (Caracas 1955) ${ }^{3}$, postula cierta «disciplina formal» para el arte narrativo y propone como modelo a seguir la labor de músicos y poetas, que partiendo de formas establecidas e impersonales llegan a expresar lo particular, sin mengua de la libertad creadora y con las «ventajas» del orden y de la claridad. La afinidad entrevista por Carpentier entre poesía y música nos pone en la necesidad de matizar la afirmación, bastante extendida, de que el hermetismo musical (repetición, estructura cerrada) difícilmente se podría conciliar con lo progresivo del arte narrativo.

Se afirma, demasiado tajantemente, que la esencia del arte narrativo es marchar siempre hacia adelante y que la música -y no la literatura- se acerca más bien al mito «en sus infinitas variaciones y su retorno al punto de partida» ${ }^{4}$. En el fondo de esta opinión, late la idea de que la rígida estructura musical «rompe el impulso de la duración». Pero no debería olvidarse que, precisamente, Bergson ${ }^{5}$-y otros ${ }^{6}$ - proponen cierta coherencia entre duración y melodía musical. En la música no todo es esquema (armónico-paradigmático; rítmico-temático-sintagmático). Lo que en puridad se denomina melodía es irreductible a espacio. La música habita un vacío. La «ausencia» de referente obliga al compositor a insistir continuamente en los mecanismos de formación, de unificación. Por ley perceptiva obvia, la innovación radical queda excluida y se hacen necesarios ciertos gérmenes espaciales de repetición. Pero junto a la repetición siempre está la variación. Es lo que decía uno de los más afinados poetas melómanos que hayan existido, E. A. Poe: «El principio es la «uniformidad»; la «variedad» es tan sólo la salvaguarda natural del principio contra su autodestrucción por exceso de respeto hacia sí mismo ${ }^{7}$. En el fondo, y teniendo en cuenta el conflicto que parece darse en el seno de la duración bergsoniana -que no puede instaurarse ni por la inteligencia ni sin ella-, cabría decir que para dar idea de tiempo se precisa siempre un germen formal. Lo informe es el horror, lo incomprensible, el silencio.

Con el lenguaje viene a ocurrir algo parecido. Su avance hacia adelante supone siempre ciertos efectos retroactivos. Todo discurso lineal deviene en forma, en Gestalt. Rodríguez Adrados habla de «la no linealidad de la expresión lingüística» ${ }^{8}$. Además, la palabra es cómplice del mundo; participa, en mayor grado que el sonido, de lo paradigmático, de lo colectivo, del espacio. De entrada, la palabra exige la sumisión de lo particular en una generalización más o menos definida, esto es, de entrada, es el lenguaje el que desbarataría la duración. Por esta complicidad con lo colectivo, con la «inteligencia», la prosa no necesita sobreactuar, exagerar los mecanis-

${ }^{3}$ Alejo Carpentier, Ese músico que llevo dentro, Editorial Letras Cubanas, La Habana, 1980, tomo III, p. 213.

${ }^{4}$ Leonardo Acosta, op., cit., p. 19.

${ }^{5}$ Henri Bergson, Ensayo sobre los datos inmediatos de la conciencia, Aguilar, México, 1963, p. 114; El pensamiento y lo moviente, Espasa-Calpe, Madrid, 1976, p. 138.

${ }^{6}$ Mikel Dufrenne, Fenomenología de la experiencia estética, Fernando Torres-Editor, Valencia, 1982, tomo I, p. 308.

${ }^{7}$ E. A. Poe, «Los fundamentos del verso», Obras en prosa, Univ. de Puerto Rico, 1956, tomo II, p. 246.

${ }^{8}$ Francisco Rodríguez Adrados, Lingüistica estructural, Gredos, Madrid, 1980, tomo II, p. 860. 
mos de unificación. Sin embargo, la poesía, que lanza sus dardos hacia el sol -más o menos-, sí necesita insistir en lo rítmico, en lo ritual, en lo unitivo: «La diferencia entre estilo y lengua, una vez más, no es radical. El estilo no es más que un uso especial de la lengua a través de una gradación que va de la lengua conversacional común a través de la literatura hasta la poesía. Pero esta gradació implica que el estilo, sobre todo en sus niveles superiores, destaca la idea de figura o «Gestalt» frente a sus partes componentes (...). Por eso lo verdaderamente característico del estilo es un grado de unificación superior al ordinrio»?

La verdadera literatura surge al ser percibida por el lector. Aquí juegan un papel principal el olvido y la memoria: «Al final de la oración (o de unidades aún más amplias) todo queda en orden: pero hay un «olvido» de completar las unidades inferiores, que ahora ya no interesan de por sí. Sólo en caso de duda se vuelve sobre ellas para obtener conclusiones sobre el total. El intérprete de textos literarios o científicos difíciles no procede de otro modo» ${ }^{10}$. Lógicamente, si algún autor tratase de aminorar esos «olvidos», estaría recalcando la unidad. Parece legítimo concluir, entonces, que la trasposición de técnicas musicales al desarrollo novelesco no implica un conflicto radical entre las características de estas dos artes «lineales»: consiste en subrayar, en hacer más explícita, la necesaria unificación de todo mensaje. Al encuadrar de este modo sus obras, Carpentier consigue plasmar ciertos rasgos míticos; pero no por ello se aniquila la «verosimilitud» histórica. Por lo demás (y no podemos entrar en ello), la dialéctica entre estructura y discurso conecta claramente con dos de los puntos básicos de la novela: memoria y proyectos.

Toda esta discusión no es gratuita. En ocasiones se ha acusado a Carpentier de proponer una visión cíclica, demasiado cíclica, de la historia, con lo que su narrativa vendría a caer dentro del pesimismo inherente a toda concepción de «eterno retorno de lo idéntico». No hay tal. La repetición se acompaña de la variación; la forma, de vida. Precisamente, lo que repugna a Carpentier es el tiempo hecho espacio, cosificado, el tiempo que es mera repetición de lo mismo, de nada. Vale recordar el tiempo del «yo social» de Bergson, el «vulgar» de Heidgger, y, por desgracia, no ya recordar, sino contemplar nuestro propio tiempo. La pesadilla de Sísifo (arriba-abajo, arribaabajo...) vertebra buena parte de la obra del cubano: «cuando salía de los estudios estaba tan saturado de mala música o de buena música usada con fines detestables, que me resultaba absurda la idea de sumirse en un teimpo hecho casi objeto por el sometimiento a encuadres de fuga, o de forma sonata» ${ }^{11}$.

Cualquier hacer del hombre es una «forma» de acceder a lo otro y a sí mismo. Pero las formas pueden degenerar. El mismo Carpentier trabajó de publicista. La publicidad del capitalismo intenta arropar su vacío esencial con la proliferación alborozada de formas nuevas, sorprendentes, huecas. Opera en la médula de nuestra capacidad de representación. Así, se hace exacto, muy exacto, el «hit» de que el medio es el mensaje.

\footnotetext{
${ }^{9}$ Ib., tomo II, p. 637.

${ }^{10} \mathrm{Ib}$., tomo II, p. 860.

${ }^{11}$ Alejo Carpentier, Los pasos perdidos, Cátedra, Madrid, 1985, p. 79.
} 
Es sabido, demasiado, que la cultura occidental tiene una cuenta por pagar consigo misma, tanto más «detestable» cuanto que siempre se halla una nueva forma de preterirla, de pasar de ella. Pero la factura resta sabor al pan, a los libros, y disfraza a la pura informática con juegos de guerra. Carpentier se embrolla menos y habla de cierto «metafísico de Heidelberg haciendo de tambor mayor de una parada» de nazis ${ }^{12}$.

Para Carpentier, la revolución es la variación historizada de la «renovatio» mítica. Sus obras, a nivel humano e histórico, promueven un viaje hacia la identidad, hacia la virtualidad no pisoteada por el tiempo baldío. Hablar de historia es hablar de relatividad, de posibilidad de «error»; pero la esperanza es factible: «Y pensaba (...) en la persistencia del mito de la Tierra de Promisión. Según el color de los siglos, cambiaba el mito de carácter, respondiendo siempre a renovadas apetencias, pero era siempre el mismo: había, debía haber, era necesario que hubiese en el tiempo presente -en cualquier tiempo presente- un Mundo Mejor» ${ }^{13}$. El deseo de plenitud torna aceptable el caos tras el que vendría un nuevo cosmos, nuevas formas -y verdaderas-. Si el caos es la destrucción de las formas que el tiempo ha agostado, es obvio que no admite en su seno resabios, prejuicios, preconcepciones. Durante mucho tiempo, América fue un mero sueño de Europa. Las repeticiones musicales que Carpentier traspone a su narrativa se prestan bien a expresar esos resabios que se observan en la evolución, en la marcha hacia adelante de los personajes. Es el error de Esteban en El siglo de las luces y el del músicopublicista en Los pasos perdidos.

Sin embargo, la recurrencia temática, el germen espacial subrayado en lo progresivo, también se aviene a expresar la sucesión de intentos de «renovatio», de recuperación del carácter no alineado. El capítulo final de El siglo de las luces recupera el inicial, ajustándose la novela a la forma sonata. El ámbito de la mansión madrileña es paralelo al de la casa de La Habana. La novela es circular... non troppo. La revolución había fracasado en Francia y en América, sumiéndose en la forma agostada del funcionariado napoleónico. Pero la revuelta madrileña aparece, en el contexto de la novela, entonada positivamente: «el personaje de Víctor Hugues, positivo en un principio, se vuelve negativo al abrazar la causa del bonapartismo. Pero en el último capítulo quien triunfa es el pueblo de Madrid alzado contra Napoleón el día memorable fijado por Goya en su cuadro más famoso» ${ }^{14}$. El viaje es un regreso al porvenir, a la virtualidad no capitalizada por esquemas vacíos, a un tiempo diverso del de Sísifo.

Llegados a este punto, se nos hace claro qué instancia subyace en la «renovatio», en la revolución: «el tiempo puede ser dominado» ${ }^{15}$. Tal es la guerra del tiempo que establece Carpentier a nivel humano, histórico y literario. El hombre, a través de la memoria, recupera su pasado, para construirse una identidad con proyectos. Antes debe quemar, abolir todo lo infructuoso de su vida anterior, los resabios y enajenacio-

\footnotetext{
${ }^{12} \mathrm{Ib} .$, p. 155.

${ }^{13}$ Alejo Carpentier, El siglo de las luces, Cátedra, Madrid, 1985, p. 318.

${ }^{14} \mathrm{Ib} ., \mathrm{p} .54$.

${ }^{15}$ Mircea Eliade, Mito y realidad, labor, Barcelona, 1985, p. 81.
} 
nes que le impedirían recobrar lo «intacto» de sí mismo. Por su parte -que no excluye la del individuo-, la historia se regenera tras el caos que suprime las formas inoperantes. Por supuesto, no se trata ya del tiempo fuerte del mito, ni de concesiones a ingenuas arcadias. Se trata -se ha tratado siempre- del reino de este mundo. Por último, a nivel creador, el tiempo se somete a espacio, a lenguaje, a formas; pero a formas que no le resten vida, que no lo hagan degenerar en una repetición inútil. La sonata literaria domina el tiempo; los temas se repiten; el «allegro» final recobra el inicial; pero la melodía instaura la vida dentro de los moldes.

Carpentier le da una forma al tiempo sin aniquilarlo; quiere construir a partir del tiempo. No hay que olvidar que otra de sus tareas fue la arquitectura, y no deja de ser curioso que, por parte de la crítica, sus obras merezcan invariablemente los títulos de musicales o de arquitectónicas: «Ciertamente, no puede tratarse de una traducción de lo musical a lo espacial, sino sólo de una espacialidad inherente a la temporalidad musical, es decir a una duración que, por ser profundamente duración, no por ello deja de estar construida. Esta espacialidad vivida por el cuerpo en la audición no se determina en figura ni es medible; ninguna representación espacial interfiere en ello ni altera la pureza de la música. Pero sí que son posibles, a partir de aquí, ciertas analogías, ciertas correspondencias entre el arte musical y el arte plástico: sobre la base de esta afinidad secreta entre lo temporal y lo espacial. Así sucede con la analogía tan frecuentemente propuesta entre la música y la arquitectura. El esquema desempeña aquí su función más precisa: el objeto que organiza lo distribuye según propociones que tienen una monumental solidez. Si la arquitectura es evocada por la música, no es por la cualidades de su material, es por lo que en sí es, entre todas las artes; porque ocupa el espacio de manera más imperiosa que cualquier otro arte, y lo ocupa haciendo triunfar en él un orden; la arquitectura llena el espacio organizándolo según leyes secretas e invisibles. Este alma de organización debida a la eficiencia de un tema es, en última instancia, común a la música y a la arquitectura; y es la organización de la duración musical la que se traduce por la organización del espacio arquitectónico» ${ }^{16}$.

Pasemos ya, sin embarazos pseudo-teóricos -pero sin «olvidar» lo dicho hasta aquí-, a anotar algunas de las características musicales de El siglo de las luces ${ }^{17}$.

\section{Contrapunto}

«Todo era transfigurado por un juego perpetuo que establecía nuevas distancias con el mundo exterior, dentro del arbitrario contrapunto de vidas...» (El siglo de las luces, p. 104).

Benedetti ha hablado en algún lugar de la «estructura catedralicia» de esta novela. Por su parte, Carpentier ha declarado la influencia en ella de la forma sonata:

${ }^{16}$ Mikel Dufrenne, op., cit., tomo I, p. 314.

${ }^{17}$ La paginación relativa a esta obra se refiere a la edición preparada por Ambrosio Fornet (Cátedra, Madrid, 1985). 
«me ayuda mi formación: me valgo de las formas musicales. El músico no puede concebir una obra que no esté perfectamente equilibrada en todas sus partes. Yo tampoco (...) Esta novela está estructurada en tres partes, como una sonata: un tema masculino, Víctor Hugues; un tema menor, Esteban; un tema femenino, Sofía» ${ }^{18}$.

Se nos permitirá el arbitrio de denominar contrapuntos a las relaciones entre los tres personajes centrales de la novela, relaciones que se tensan, se relajan, etc., a lo largo de la evolución de la historia. Las variaciones sobre ciertos motivos que se repiten contribuyen a dar solidez formal a la obra y, a la vez, hacen evidentes los cambios, los nuevos contextos en lo progresivo. Hay que advertir que Carpentier suele penetrar las mentes de Esteban y Sofía; no así la de Víctor. Este se focaliza generalmente por medio de acciones, diálogos directos y, sobre todo, a través del prisma de los jóvenes. Víctor, el tema mayor de la sonata, deja sentir su presencia a lo largo de casi toda la obra. La cuestión no carece de interés. Mientras que la relación Esteban-Sofía permanece como telón de fondo o cumple una función de enlace, Carpentier establece una visible conexión entre los contrapuntos Esteban-Víctor y Sofía-Víctor, hasta extremo tal que éste último viene a ser una variación, breve y rítmica, de aquél. Por ello, analizaremos ambos al mismo tiempo -sin olvidar que son sucesivos-, dejando para más abajo la relación entre los primos.

\section{Esteban-Víctor; Sofia-Víctor}

Esteban sigue paso a paso la evolución de Víctor, desde el ideal revolucionario («renovatio», mito del Mundo Mejor) hasta el aburguesamiento institucional (mito de Sísifo). Acrecido junto al francés, el joven se lanza a la aventura, al viaje, pero, cada vez en mayor medida, irá «regresando» a los prejuicios, a los resabios adolescentes. El contrapunto se resumiría, entonces, como enfrentamiento entre teoría inoperante y praxis política. Por el contrario, Sofía, al iniciar su prueba de fuego, se encuentra en Cayena con el Víctor sometido al clima reaccionario thermidoriano. Se enfrentan los anhelos de praxis revolucionaria de la mujer -intuitiva, sin resabios-, y la franca contrarrevolución de Víctor.

Al comienzo, Esteban se siente cautivado por la masculina firmeza y las ideas del francés: «Es todo un personaje (p. 113). Lo mismo opinará Sofía poco antes de embarcarse para Cayena: «Un personaje extraordinario, a pesar de todo» (p. 346). La variación se sitúa en el «a pesar de todo», que engloba los errores de la revolución.

Por mediación de Víctor, el mestizo Ogé cura la afección asmática de Esteban -reflejo de la que padeció Carpentier-, posibilitándole su apertura hacia el mundo. Sorprende que una novela de tamaña extensión aparezca orquestada hasta en sus más nimios detalles. Consérvese en la «memoria» que las matas de reseda, arrancadas de raíz por Ogé, habían estado absorbiendo las energías del enfermo: «era matado lentamente por las flores amarillas que se alimentaban de su materia» (p. 122). La

${ }^{18}$ Alejo Carpentier, El siglo de las luces, op., cit., p. 55. 
confianza de Esteban en las nuevas ideas es total. La búsqueda de la libertad torna aceptable el caos que precederá al nuevo cosmos; justifica «la inminiencia de un Gran Incendio que (...) aceptaba como una purificación necesaria, como un Apocalipsis que estaba anhelante de presenciar cuanto antes, para iniciar su vida de hombre en un mundo nuevo» (p. 147). Así, partirá optimista hacia «la Columna de Fuego que guía las marchas hacia toda tierra prometida» (p. 167) -variaciones sobre un tema-.

También para Sofía es Víctor la causa de la apertura hacia lo exterior: «Y por primera vez se vio Sofía fuera, entre mansiones que la noche acrecía en honduras, altura de columnas, anchura de tejados» (p. 116). Claro que, al comienzo, Sofía es más propensa que su primo a escandalizarse y ruborizarse. Durante esta primera salida, no soporta el truculento espectáculo nocturno de la ciudad: «Aquel mundo le era tan ajeno que lo miraba como una visión infernal, sin relación con los mundos conocidos. Nada tenía que ver con las promiscuidades de aquel atracadero de gente sin fe ni ley. Pero advertía, en la expresión de los varones, algo turbio (...) Era como si «eso» no les repugnara tan profundamente como a ella» (p. 118). Ni que decir tiene que tampoco le agrada el excesivo desparpajo de Víctor.

Pero la noche del huracán en La Habana es una clausura y un inicio. Sofía no se deja seducir, pero se percata de que «la habian visto como Mujer, cuando no podía verse a sí misma como Mujer» (p. 137). Poco a poco, la nueva realidad que Víctor representa le hace perder los temores. No es de extrañar que, durante el viaje en el Arrow hacia Port-au-Prince, se entrevea una encandilada variación sobre el escabroso motivo del «eso»: «había sido eso, con toda su brutalidad, lo único realmente importante (...) en su vida» (p. 157). Por fin, en un camarote de la nave -recuérdese esto-, se consuma la unión carnal.

Se observa, pues, que al principio las voces de los personajes corren más o menos paralelas. Sin embargo, el contrapunto Esteban-Víctor pronto comienza a manifestar tensiones. En París, los amigos se ven menos. Estalla el conflicto entre la teorización pseudotrascendental de la masonería -que ya había sido insinuada en la amistad Víctor-Ogé- y las exigencias políticas de la revolución. Víctor inicia su escalada hacia las cumbres jacobinas (Billaud, Collot d'Herbois, Robespierre): «la masonería es contrarrevolucionaria. No hay más moral que la moral jacobina» (p. 176). Esteban necesita en demasía el apoyo del francés, «se sentía más sólido, más hecho, más levantado en estatura masculina, junto a Víctor Hugues» (p. 166). El contrapunto se complica con los inveterados resabios del que antaño era cuidado, e incluso bañado, por su prima. Desde siempre, hay en Esteban un deseo inconsciente de ser protegido, que desemboca en una confusa mezcla de admiración, envidia y celos hacia la recia masculinidad de Víctor. En la frontera vasca, «privado de su calor, de su dureza, de su ímpetu, del relumbre de sus contactos directos con un Billaud, con un Collot (...) Esteban tenía la impresión de decrecer, de achicarse, de perder toda personalidad» (p. 185) -variaciones de estatura-. En la frontera, entrevé su incapacidad para la acción y siente las primeras nostalgias del hogar y de Sofía, nostalgias que incluyen resabios, pero también el deseo de superar las contradicciones en que empieza a caer la revolución mediante el «regreso» a la virtualidad intacta. 
También Sofía intentará realizarse confiando excesivamente en los proyectos de Víctor: «no podía un hombre de su temple sino estar madurando grandes empresas: proyectos en los cuales pudiese cada cual hallar su cabal medida» (p. 358). Cree que Víctor está intentando trasladar la revolución a las tierras firmes de Amércia, esto, es que el primer intento de «renovatio», fallido en Europa, está pugnando por actualizarse otra vez: «Nacía una épica que cumpliría en estas tierras, lo que en la caduca Europa se había malogrado» (p. 371). Ocurre, empero, que las epopeyas suelen quedar truncadas.

La decepción que embarga al jefe de los montañeses, coronel Martínez de Ballesteros, pre-figura el fracaso final de Esteban. Cuando Ballesteros se queja de los continuos -y contradictorios- exterminios que ha causado la revolución, Esteban todavía esgrime la necesidad del caos que permitirá el acceso a un nuevo orden: «La humanidad saldra regenerada de este baño de sangre» -variación púrpura del tema apocalíptico-. Pero el coronel replica: «sobre todo, no me venga con el Mar Rojo de Saint-Just, que eso no pasa de ser mala retórica» (p. 187). Mala retórica significa forma que ha dejado de ser operante, simbolismo vacío, esquema de Sísifo. Esta escena es estructuralmente análoga a otra ocurrida entre Víctor y Esteban. El francés intenta justificar políticamente el traslado de la guillotina a las Antillas, pero el joven responde: «La letra con sangre entra» (p. 199) -variación cínica del motivo-. Todavía interesa anotar otra escena afín a las anteriores. Esteban, fracasado, vuelve a La Habana y se encuentra con que Sofía aún cree que «nada grande se hacía en la Tierra sin derramamiento de sangre», opinión que ofusca al otro: «Eso lo dijo Saint-Just antes que tú» (p. 331).

También será el coronel Ballesteros el primero en percatarse de que la revolución está perdiendo sus originales afanes universalistas: «iMalditas las ganas que tienen ya de hacer una revolución universal!» (p. 186). La resolución de este motivo ocurrirá mucho después, cuando Sofía compruebe que Víctor no va a hacer germinar la revolución en las tierras de América: «no seré yo quien pretenda llevar la Revolución a Lima o a la Nueva Granada» (p. 389).

El reencuentro entre Esteban y Víctor en Rochefort es deprimente para aquél: «Víctor abrazó fríamente al joven, al cabo de la larga separación (...) "Hablaremos luego -dijo (...)- Vete a la intendencia". Rectificó: "Vaya a la intendencia y espere órdenes mías"» (p. 191). El trato que recibe Sofía al llegar a la Guayana es una variación sobre el tema de la educada frialdad de Víctor: «le entregaron un breve mensaje, garabateado en papel de oficio: Bienvenida. Mañana irá un coche a buscarla. V. Cuando Sofía esperaba recibir una impaciente llamada, le venían esas frías palabras» (p. 347). Al día siguiente, el «Gran Encuentro» queda chafado por la impertinencia de los cerdos en desbandada. Sin embargo, un cambio de entonación los arrastra hacia la consumación carnal. Se evoca aquí -recuérdese- el primer contacto de los cuerpos en el Arrow y se compara la casa de ahora con la nave de antaño: «Oíase el correr de las aguas en una represa cercana. Nave era la casa batida por el oleaje de árboles» (p. 379). Pero el concepto de amor también ha variado. Ahora respondía a impulsos sensuales «que en nada solicitaban el consentimiento del espíritu» (p. 379). 
En la travesía hacia la Guadalupe, la tensión entre los hombres se complica afectiva e ideológicamente. El francés tacha a Esteban de «discutidor», esto es, de resabiado, aunque él mismo, al pretender justificar políticamente todas las contradicciones de la revolución, esté cayendo en un esquema igual de vacío que el de las preconcepciones. Sofía también discutirá con Víctor, pero desde un plano más vital, menos acomplejado. Le echa en cara lo absurdo del Concordato y del Decreto del 30 Floreal, que autoriza -variación total- de nuevo la esclavitud. Víctor sigue justificándose por razones políticas decepcionantes. Las recriminaciones de Sofía bajo el retrato de Bonaparte son una clara variación de las de Esteban bajo el de Robespierre. El acomodaticio aburguesamiento de la revolución es evidente. También es visible que Carpentier calcula matemáticamente sus obras, sin faltar a la fluidez.

Tanto en Esteban como en Sofía se produce ese peculiar sentimiento de aversión hacia el ser amado cuando éste llega a decepcionar. Esteban ausculta las debilidades del comisario con una complacencia enfermiza. El descubrimiento de que Víctor intenta emular el porte del Robespierre retratado en su camarote «fue como una leve victoria compensadora para Esteban» (p. 200). Por su parte, Sofía se goza del fracaso de la expedición a la caza de los negros cimarrones (p. 397). Cuando Víctor enferma a causa del mal egipcio, Sofía lo halla «débil, lloroso, asustado (...) Frente al miedo del otro su propia persona se acrecía» (p. 399).

Con todo, el conflicto afectivo de Esteban es más grave que el de su prima. Se agudiza al comprobar la propia cobardía. Durante el bombardeo de Jarvis a la Guadalupe, se ve muy claro que el apocalipsis y las pruebas de fuego con las que soñara al principio se han vuelto contra él. Por otro lado, la admiración hacia Víctor se mezcla con la envidia y la emulación. En cierta ocasión, el agente, trasponiendo su voluntarismo en un portazo, echa a Esteban del despacho, con las consiguientes burlas de las sirvientas. Una de ellas, mulata, le pregunta con sorna: «¿Monsieur Víctor faché?» (p. 221). El motivo se repetirá con una variación socarrona. Esteban exhibe su fuerte voluntad... ante una mujer -mulata también-. Atalía, descubierta en sus espionajes, es airosamente azotada; «arrepentida y, acaso por vez primera, enamorada», lo ayuda a vestirse «tratándolo de Mon Doux Seigneur» (p. 245).

Las relaciones entre los personajes continúan deteriorándose, aunque el contrapunto se relaja en algunos aspectos, debido a la sumisión de las vidas en el tiempo infuctuoso de Sísifo. Esteban sublima su fracaso revolucionario a través de aventuras paisajísticas y de sus relaciones carnales con Atalía. Se trtata del tiempo lento, repetitivo, sentido como prisión, en el que también sucumbirán Víctor y Sofía. El francés, tras la caida de Robespierre, se ha malacostumbrado a dormir exageradas siestas entre sus fámulas y a engordar sin consideración. El deseo de volver a casa traumatiza a Esteban. Víctor también «regresa» a antiguas inclinaciones. Los beneficios nada desdeñables de la piratería y los monopolios que intenta establecer en la Guadalupe constituyen una decepcionante variación del antiguo negociante de Portau-Prince. El incendio de su panadería, que había sido símbolo del caos necesario, de la prueba de fuego, no consiguió abolir todos sus resabios. Por su parte, Sofía se dedica a consumir literatura prerrománica para olvidar «el aborrecible tiempo detenido». 
Por fin, Víctor es llamado desde París para rendir cuentas. La tensión decrece. Al principio, Esteban se sentía «más hecho» junto a Víctor. Ahora considera a éste una voluntad ajena. Es el final del contrapunto entre ambos: «Se rompían los nexos» (p. 281). En Cayena, el joven se encuentra con Billaud -el paralelo estructural de Víctor- Billaud, antaño investido de poderes, condenado después a la Guayana, se verá nuevamente restituido, prefigurándose así la restitución de Víctor. No es extraño, entonces, que Billaud se haya ido forjando el mismo concepto negativo sobre los negros que Víctor (p. 286). Finalmente, Esteban pasa a Paramaribo, donde se emplea la medicina científica para amputar miembros a esclavos cimarrones -variación cínicamente cortés de Cayena-.

El excurso que supone en la novela la narración de la epopeya fracasada de los Caribes adquiere un valor simbólico. El mito del Mundo Mejor sufre variaciones, pero es siempre el mismo. Moisés no entró en la tierra Prometida, ni los caribes, ni Esteban: «y a un Mundo Mejor había marchado Esteban (...) encandilado por la Gran Columna de Fuego que parecía alzarse en el oriente. Y regresaba ahora de lo inalcanzable con un cansancio enorme» (p. 318).

Con Sofía se repite el fracaso, pero con una variación capital. Para Esteban, el regreso a casa, más que un deseo de acceder nuevamente a la virtualidad plena anterior a las formas agostadas-, era una cobarde caída en viejos resabios adolescentes. De hecho, regresa a La Habana. Sofía, por el contrario, prefiere seguir en la brecha: «Jamás volveré a una casa de donde me haya ido en busca de otra mejor» (p. 401). En el caso de Esteban, lo nexos se rompieron con inconsciente ofuscación, involuntariamente -al ser Víctor reclamado desde París-. En el caso de Sofía, la decisión es propia. La mujer se entrega al romántico oficial De Sainte-Affrique: «Volvía a ser dueña de su propio cuerpo, cerrando con un acto a su voluntad debido, el ciclo de una larga enajenación» (p. 403). Por ello, la casa de Madrid supone para Sofía el acceso a su ser intacto, esto es, un nuevo comienzo. Creemos haber mostrado suficientemente que ambos contrapuntos repiten un mismo esquema, pero con variaciones nada despreciables.

\section{Sofía-Esteban}

La relación entre ambos constituye, en los comienzos, una suerte de idilio maternal, asexuado, de refugio afectivo, en el que las coordenadas espacio-temporales son creaciones arbitrarias con respecto a las del exterior. Sin embargo, todo ello comporta una potencialidad sensual que desembocará en el conflicto. Sofía, en su papel de madre de Esteban, «no vacilaba en desnudarlo y darle baños de esponja» (p. 100). Un posible marido para la mujer era impensable; implicaría una degeneración de la virtualidad plena. La carne «debía permanecer intacta» (p. 103). No obstante, algunos detalles preludian la evolución posterior. En el arbitrario orden del salón desorden con respecto al exterior-, Sofía ocupa una meseta intermedia «con los tacones al nivel de las sienes de su primo (...) donde podía repantingarse a gusto, 
desabrocharse, correrse las medias, recogiéndose las faldas hasta lo alto de los muslos» (p. 104). También a Esteban lo vemos alguna vez «glosando un encendido versículo del Cantar de los Cantares».

Con la aparición de Víctor, el idilio asexuado comienza a resquebrajarse. El motivo de los baños de Esteban sufre una pudorosa variación: «Sofía (...) cuidaba ahora, por un creciente sentimiento de pudor, de no asomarse a la azotea cuando sabía que el mozo se bañaba allí» (p. 125). Esteban deambula cada vez con más frecuencia por las calles de prostitución portuaria, hasta que «una tarde, al fin, la puerta azul de la casa se cerró sobre él» (p. 127). El fragmento contiene la clave de otro muy posterior. En el tiempo detenido del Caribe, Esteban se siente prisionero, «condenado (...) a oler los olores de su infancia, a encontrar en casas (...) iluminaciones peculiares ( $¡$ Oh, ciertos embadurnados anaranjados, ciertas puertas azules!) el marco de su adolescencia sin que lo suyo (...) le fuese restituido».

El contrapunto se interrumpe durante los años que Esteban pasa fuera, aunque éste bien pronto empieza a sentir nostalgias del hogar. Al regresar, cree poder recuperar el ámbito cerrado del pasado, pero las variaciones son evidentes. Sofía se ha casado, rompiendo una vez más el misterio de la carne intacta, y sus anhelos de acción no coordinan ya con los resabios del primo. Tras la tormenta en la finca de la familia de Jorge -el nefasto marido-, el motivo del idilio asexuado sufre una aguda variación, pues se actualiza su virtualidad sensual también para Esteban. Sofía se percata de que ha sido «mirada como mujer» (p. 339) por su primo, lo cual resulta inaceptable. La escena resulta, a la vez, una sutil variante del primer intento de seducción por parte de Víctor -también en atmósfera tormentosa-, cuando Sofía observa que «la había visto como Mujer, cuando no podía verse a sí misma como Mujer» (p. 137). Al primo no se le permiten deslices. «Lo has roto todo» (p. 339) le dice, marcando uno de los momentos de máxima tensión en la relación.

Los cuidados extremos que antaño prodigara Sofía a su primo van ahora dirigidos a su esposo enfermo -variación recelosa del motivo-. Pero el verdadero rival de Esteban es Víctor, cuyo fantasma sigue pesando sobre la casa. Al embarcarse para Cayena, Sofía «se revelaba a Esteban, de pronto, en una dimensión larvaria (...) de hembra entregada (...) gozosa bajo el peso de un hombre» (p. 356). Se trata de una irónica inversión de aquella Sofía de los inicios, tan prontamente escandalizable ante lo escabroso del «eso». El timorato es ahora Esteban, que ve arruinado su intento de recuperación del ámbito adolescente.

La relación se interrumpe durante la estancia de Sofía en Cayena y se recupera en el último capítulo, reconstruida merced a las pesquisas de Carlos en Madrid. El contrapunto relaja su tensión regresando a la armonía inicial. Algunos indicios asemejan la relación de los primos en Madrid al antiguo idilio de la casa habanera. La estructura novelística es perfectamente cerrada, lo que no quiere decir que se trate de un retorno de lo idéntico. Esteban vuelve del presidio de Ceuta aquejado de nuevo con el asma de la infancia. Paradójicamente, se alivia «al fumar cigarrillos liados con pétalos de la Flor de Campana» (p. 409). Este motivo es la inversión de otro muy anterior. Recordemos que, según la prescripción del mestizo Ogé, era la flor de reseda 
lo que provocaba el asma del adolescente. La recuperación del ámbito inicial también se entrevé en otros factores. La «futura llama» que aparece en los subrayados de René (p. 410) es una variación mucho más intimista y sentimental que el inicial fuego épico, con sus apocalipsis y columnas ígneas. Según el testimonio de una camarera, ambos vivían «en una apacible y cariñosa intimidad» (p. 410), «se agarraban de la mano, así, como pueden hacerlo dos hermanos», y, a causa de la dolencia de Esteban, «ella, más de una vez, había permanecido a su lado hasta el alba» (p. 411). Sintomático es también el siguiente párrafo: «Sólo sorprendía a las gentes que una mujer tan guapa no se resolviera a casarse» (p. 411). Como en el idilio adolescente, un marido es impensable. Volvemos al motivo de la carne intacta. Como el primero, este otro ámbito intimista se rompe también, pero no por mano de voluntades ajenas. Dijimos arriba que la revuelta madrileña aparecía entonada positivamente. La muerte confiere a los jóvenes cierto carisma heroico. «Las palabras no caen en el vacío».

\section{Variaciones sobre motivos recurrentes}

Esta técnica, de la cual ya se han visto numerosos ejemplos al estudiar los diversos contrapuntos de la sonata, contribuye a apuntalar la sólida arquitectura de la obra, pero también, en virtud de la íntima relación existente entre forma y devenir, entre espacio y tiempo -señalada en la «Introducción»-, hace evidente lo progresivo, marcando los distintos puntos de la evolución o desarrollo de los tres temas fundamentales. Un análisis que pretendiera comentar todos los motivos recurrentes de El siglo de las luces doblaría el volumen de la obra. Hemos escogido tres de los más significativos en sus apariciones principales. Pero hay muchos más: el cuadro «La explosión en una catedral», la aldaba, comidas y bebidas, olores, etc. Todos ellos, una vez tramados en el discurso, confieren a la novela una estructura casi matemática.

\section{Las nuevas ideas}

La evolución de estas ideas, que intentan permitir el acceso a la «renovatio», supone, a la postre, un «regreso» a viejos resabios, a formas vacuas, al tiempo infructuoso de Sísifo. No obstante, habida cuenta de la entonación positiva con que se orquesta el levantamiento madrileño, se hace cierto el epígrafe del ZOHAR que encabeza la novela: «Las palabras no caen en el vacío». Las declaraciones de Carpentier ratifican esta opinión: «¿El principio que sustenta la novela? Puede resumirse en esta frase: Los hobres pueden flaquear, pero las ideas siguen su camino y encuentran al fin su aplicación» ${ }^{19}$.

Al librarse de la rígida autoridad paterna, los jóvenes inician un tímido contacto con el exterior, merced a los libros que llegan a la casa, «destinados a constituir una 
biblioteca de ideas nuevas» (p. 101), merced al Gabinete de Física de Esteban, etc. Pero todo ello se mantiene inicialmente dentro de un contorno cerrado, lúdico, con categorías arbitrarias y sin indicios de praxis: «Todo era transfigurado por un juego perpetuo que establecía nuevas distancias con el mundo exterior dentro del arbitrario contrapundo de vidas...» (p. 104). Víctor supone la verdadera apertura hacia lo externo, hacia las coordenadas espacio-temporales de la historia. Esteban juega con su gabienete de física -lo que no deja de ser paradójico-. Será el francés el que ilustre teorías, analice el espectro, etc. Las ideas comienzan a perder su ambigüedad teórica para tratar de encarnar en la realidad.

Paralelamente, el transcendentalismo masón intenta ser sustituido por la política a secas. Víctor choca con su amigo Ogé, que pretende «desarrollar las fuerzas transcendentales dormidas en el hombre» (p. 147). El mismo enfrentamiento, con una variación intensiva, se da en París entre Esteban y Víctor: "La masonería es contrarrevolucionaria» (p. 176). No obstante, pronto se inicia el «regreso». El curso político de la revolución se desvía en contradicciones, provocando pasmosas variaciones. Paulatinamente, se vuelve al transcendentalismo antaño estigmatizado e, incluso, a cierto tipo de religiosidad impuesto por Robespierre. Tras el escalón de la Fiesta del Ser Supremo y la Inmortalidad del Alma, se resuelve esta armónica cadena de variaciones en el Concordato final entre Bonaparte y el catolicismo.

Las mismas desconcertantes variaciones se producen con el motivo de los esclavos, liberados primero, vigilados estrechamente después y vueltos a esclavizar al fin, por los mismos que portaron el decreto de abolición, cuya inversión es el Decreto del 30 Floreal.

La revolución se aburguesa. El antiguo comerciante de Port-au-Prince, que ya hacía escarceos en el contrabando, vuelve otra vez a la rapiña y a los monopolios, para acabar como mero burócrata del Directorio. Su paralelo, Billaud, comercia con esclavos. Incluso de Robespierre se supo que, en el extranjero, «tenía bienes particulares a buen recaudo».

\section{La guillotina}

Es de sobra conocida la importancia que en la obra de Carpentier manifiesta el tema del teatro. En última instancia, se alude a la necesidad del hombre de enfrentar la realidad por medio de representaciones, que pueden ser válidas o degenerar en la hueca hipocresía, en la forma sin sostén, en la vacua retórica. Exceptuando el preludio sobre la «Puerta-sin-batiente» que encabeza la novela, la primera visión de la guillotina ocurre en la frontera vasca y connota ciertos tintes tragicómicos: «Lejos de su ambiente mayor, lejos de la Plaza salpicada por la sangre de un monarca, donde había actuado en Tragedia Trascendental, aquella máquina (...) cobraba, al actuar, el lamentable aspecto de los teatros donde unos cómicos de la legua, en funciones provincianas, trataban de remedar el estilo de los grandes actores de la capital» (p. 184). 
En el viaje a Las Antillas, la guillotina, embalada aún en la proa del barco, varía sus tintes hacia otros más lunáticos y sombríos: «Una de ellas (cajas) al ser abierta, recogió la luz de la luna en una forma triangular, acerada, cuya revelación estremeció al joven» (p. 199). Y de las tinieblas pasamos a las «luces». Cuando los militares de la tripulación se muestran reacios a tomar la Guadalupe, Víctor impone su autoridad política. El definido perfil del arma simboliza la neta investidura de poderes del agente: «acercándose a la guillotina, hizo volar la funda (...) haciéndola aparecer, por primera vez, desnuda y bien filosa la cuchilla, a la luz del sol» (p. 205).

En la Guadalupe, donde los habitantes estaban acostumbrados «a convivir con el amo de turno», la guillotina se tranquiliza un tanto. Por ello, volvemos a la entonación jocosa del motivo. Monsieur Anse, el verdugo, demostró su saña cruenta en Rochefort; pero, curiosamente, se trata de «un mulato de finos modales, educado en París, violinista ameno, cuyos bolsillos siempre cargaban caramelos para los niños» (p. 218). También recuerda oportunamente Carpentier -siempre musical- que el mecanismo de la funesta máquina había sido inventado «por un factor de clavicordios». Todas estas morosidades joco-serias no obstan para que, tras la derrota de los ingleses, la saña del arma adquiera su espeluznante culminación. Cerca de un millar de franceses que habían apoyado al enemigo son ajusticiados. Lo jocoso varía en cínico. El propio verdugo «contaba a Esteban que la guillotina no podía usarse para ejecuciones en masa» (p. 223).

Con el comienzo del terror en la isla, se manifiesta que la guillotina sabe realizar su papel cuando es necesario; pero los papeles, las formas y las representaciones suelen de-generar. Las variantes jocosas del motivo prefiguran el aburguesamiento y las contradicciones: «El patíbulo se había vuelto el eje de una banca, de un foro, de una perenne almoneda. Ya las ejecuciones no interrumpían los regateos (...) Se vendían, entre perejiles y oréganos, unas guillotinas minúsculas, de adorno (...). Los niños (...) construían unas maquinillas destinadas a la decapitación de gatos» (p. 226). No hay que olvidar que el adorno es sinónimo de retórica hueca, de falsa representación, de forma muerta, de publicidad... Por lo demás, la guillotina prefiere segar ahora «a ras de suelo» (p. 227), sobre todo el cuello de esclavos que se acogen ingenuamente al decreto de abolición -a punto de des-variar en el decreto del 30 Floral-. En fin, la máquina sigue, orquestadamente, los pasos de los demás motivos, los pasos del fracaso revolucionario, los pasos de ese Víctor que engorda y recobra su vieja estampa de negociante: «También la guillotina se había aburguesado, trabajando blandamente, un día sí y cuatro no» (p. 263). Estas variaciones, al insertarse en la memoria, dan idea de la evolución del tiempo -desde las ejecuciones masivas al ocio-.

El artilugio, que había tenido un inicio tragicómico y provinciano, un inicio de representación fallida -recuérdese la «mala música o (...) buena música usada con fines detestables»-. se acerca de nuevo a ese contexto hacia el final: «Había llegado el Teatro a la ciudad sin teatro y como había que hacer teatro se tomaron las providencias oportunas (...). Como la plataforma de la guillotina podía servir de buen escenario, la Máquina fue trasladada a un traspatio cercano, quedando en poder de las gallinas» (p. 274). Por fin es totalmente desarmada. Pero todavía, en Cayena, 
presencia Esteban una horripilante variación de la guillotina. No se muere de un tajo, sino a plazos; no cruenta, sí cruelmente: la «guillotina seca».

Después de Esteban comienza su andadura Sofía. La guillotina todavía se ve en La Habana como una esperanza, como un baño de sangre inexcusable, como el caos necesario para la instauración de un nuevo orden. Dice Sofía: «Ojalá pudiéramos levantar una, muy pronto, en la Plaza de Armas de esta ciudad imbécil y podrida» (p. 332). Pero sus deseos son anacrónicos con respecto a Esteban y con respecto a Víctor; anacrónicos porque ella todavía intenta acceder al tiempo pleno de la «renovatio», mientras que los otros chapotean en el tiempo de Sísifo. La revolución no germina en Amércia. Víctor es un absurdo funcionario de Napoleón. Estamos, de nuevo, en el contexto de farándula: «Y lo tragicómico del caso era que, para demostrar sus buenas disposiciones, Víctor Hugues había llegado a Cayena con una banda de música ostensiblemente instalada en la proa del barco, allí mismo donde, antaño, se había erguido la guillotina llevada a la Guadaluple» (p. 345). Una banda ostensible; música publicitaria; metafísico de Heidelberg haciendo de tambor mayor...

\section{Trajes y disfraces}

... Ideas degeneradas; forma vacía que conforma o deforma a Sísifo; traje sin cuerpo.

Al iniciarse la novela, se os ofrece un espectáculo funerario: «volvía el albacea a su recuento de responsos, crucero, ofrendas, vestuario, blandones, bayetas y flores, obituario y réquiem -y había venido éste de gran uniforme, y había llorado aquel y había dicho el otro que no éramos nada» (p. 87). El luto por la muerte del padre no parece ser muy aceptado al principio. Sofía aparece como prisionera en sus trajes negros más grandes de la cuenta (p. 91). Sin embargo, cuando los jóvenes se aclimatan en su ámbito cerrado, el luto varía de función: «Tomaban el luto como socorrido pretexto para permaneer al margen» (p. 165). Pero ya dijimos que en la atmósfera fetal se entreveían indicios de la posterior apertura hacia lo exterior. En la casa habanera suelen hacer fiestas de disfraces. Víctor, prefigurando su cometido e indumentaria posteriores, se disfraza de «Mucio Scévola, de Cayo Graco, de Demóstenes» (p. 113). El que ahora se disfraza de legislador, de tribuno, de magistrado, etc., será después el «Investido de Poderes».

Durante el huracán en La Habana, el francés «hizo observar a Sofía que estaba sencillamente asquerosa con aquel vestido ensuciado por aguas inmundas, con esas medias enlodadas (...). Sofía se fue a su tocador y pronto regresó algo peinada, envuelta en una dormilona» (p. 133). Semejante motivo se repetirá después en Cayena.

El tema de las preferencias indumentarias de Víctor sufre una profunda variación en el viaje desde Rochefort a Las Antillas. Esteban, con ciertos resabios, observa maliciosamente que Víctor trata de emular el porte del retrato de Robespierre: «Así, el hombre que en otros días se hubiera disfrazado tantas veces de Licurgo y Tesmístocles (...) hoy, investido de poderes (...) trataba de remedar a otro hombre» (p. 
200). La observación procede más de los resabios del joven que del hecho de que Víctor haya degenerado todavía -el fracaso vendrá cuando quiera imitar el porte vacuo del retrato de Napoleón-. Podríamos decir que Esteban envidia la posición de Víctor con proféticos pensamientos: «El Traje se te ha subido a la cabeza (...). Cuidado con la borrachera del Traje: es la peor de todas» (p. 203).

Efectivamente, la indumentaria fracasa; se convierte en el símbolo de un vacío. La variación que toma este motivo en la Guayana es de una truculencia pasmosa. A Cayena han ido a parar muchos antiugos investidos: «Los recién llegados se acorazaban de dignidad, agigantados por el Traje, en un mundo de seres encorvados y desnudos» (p. 297). Pero no tardaba en sobrevenir la destrucción: «Horadados por una polilla invisible, el uniforme del Jefe Militar, la casaca del Magistrado, la última camisa del Tribuno, se quedaban en las manos un buen día, en jirones» -obsérvese que el recuento de confecciones incluye a los diversos personajes que Víctor gustaba «representar»-. Los personajes acaban muriendo «envueltos en andrajos» (p. 299). Sólo Billaud, el inclaudicable, guarda la compostura, lo que prefigura su nueva investidura y la de Víctor.

Tras el fiasco revolucionario, Esteban intenta reconstruir, en la casa habanera, el antiguo idilio familiar y trata de aprovechar el luto por la muerte de Jorge -esposo de Sofía- para refugiarse del exterior, como al principio ocurriera con el luto por la muerte del padre. Carpentier retoma el motivo fúnebre inicial, entonándolo en hipotético: «El luto, cerrando la casa, volvería a crear la atmósfera de otros días. Se regresaría, acaso, al desorden de antaño, como si el tiempo se hubiese revertido. Tras de la larga noche del velorio; tras del entierro, con sus responsos, crucero, ofrendas, vestuario, blandones, bayetas y flores, obituario y réquiem -y se comentaría que había venido éste de gran uniforme, y que había dicho aquel, y que había llorado el otro, gimiendo que no éramos nada (...)-: tras de la despedida del duelo (...)., volvería a establecerse un vínculo natural con lo que atrás había quedado» (p. 349).

Espera, pues, Esteban que el luto, las desordenadas comidas, los juegos, vuelvan a propiciar el antiguo refugio afectivo. Pero Sofía no está para tales resabios. La variación del motivo es tal que el joven queda anodadado. En un ciclón, trató Víctor de seducir a Sofía. Ahora, durante otro ciclón, Esteban trata de salvar del agua las banastas continentes de la ropa «de luto» de Sofía; pero todo señala hacia la juvenil incontinencia de Sofía y Víctor: «y cuando esperaba meter las manos en tinieblas de paños negros, le salió al encuentro una fiesta de telas claras, rasos, sedas y adornos (...) finísimos tejidos (...) y prendas íntimas de una delicadeza extrema» (p. 352).

En el reencuentro de Sofía y Víctor en Cayena, se repite una situación anterior. Durante el primero de los ciclones arriba mencionados, el francés había recriminado a Sofía por su traje enoladado. Esa noche había tratado de seducirla. En la Guayana, el ciclón se convierte en «porcina barahúnda» (p. 376) y Víctor manda igualmente cambiarse de traje a Sofía. También se entregan al amor, pero es difícil olvidar ese contexto de ironía y decepción.

Las relaciones entre ambos se vienen abajo. El motivo del traje adquiere una dimensión patética cuando Víctor, cegado por el mal egipcio, acaba confensado su fracaso: «Quiero que me entierren -decía- con mi traje de Comisario de la Convención (...). He vestido tantos trajes que ya no sé cuál me corresponde (...). Pero hay uno que 
prefiero a todos los demás: éste. Me lo dio el único hombre a quien, alguna vez, puse por encima de mí. Cuando lo derribaron dejé de entenderme a mí mismo» (p. 399). Incluso en sus últimos momentos, Víctor es consciente de que haber abandonado el radicalismo jacobino ha supuesto para él la alienación. El que gustara disfrazarse de tribuno poderoso acaba convertido en «parricida» de tragedia antigua». La revolución ha desembocado en formas baldías, en teatro de esperpento, en traje sin soporte corpóreo: «Colocado como estaba, sobre una butaca de tapicerías rotas, con las bragas en su lugar, la casaca con banda tricolor terciada, el sombrero puesto sobre muslos ausentes, parecía una reliquia de familia de las que hablan, por sus formas vacías de osamente y carne, de la estampa de un hombre desaparecido que, en un tiempo, hubiese desempeñado un gran papel» (p. 402).

\section{La sonata}

Creemos necesario un somero comentario sobre el concepto de sonanta. Esta estructuración del material sonoro, consolidada en el clasicismo, ha ejercido en la historia de la música una influencia sin igual. Como bien comprendió Felipe Manuel Bach -es un mero hito-, tras enunciar un tema musical es neceseario variarlo para evitar una monotonía repugnante a nuestra percepción, pero, más tarde, hay que retomarlo de nuevo, ya que una innovación continua carecería de sentido. Así surge la estructura ternaria de la sonata, que posteriormente se verá enriquecida por la adición de un segundo o incluso un tercer tema, que permiten la variedad y el contraste. Ya comentamos más arriba la íntima relación entre forma y devenir: «los "temas" son a la melodía lo que los esquemas son a la armonía y al ritmo; asumen una doble función: dan una embrionaria "materia-sujeto", átomo de sentido que la melodía desarrolla, y aseguran también a la música, organizándola, el elemento de espacialidad sin el que el objeto musical, que en sí mismo no es espacial, no poseería objetividad y peligraría su identidad por el riesgo de deshacerse (...). Brelet ha demostrado que, fuera del tema, la duración se desmigajaría, se desvanecería, es decir que en el fondo, un devenir rebelde a la forma no sería tal devenir» ${ }^{20}$.

La sinfonía, el concierto, las composiciones camerísticas, etc., se apoyan en el concepto de sonata. Ahora bien, el término «sonata» reviste cierta ambigüedad. En sentido técnico, se llama «forma-sonata» o «allegrosonata» a una estructura musical con tres partes: Exposición, en la que se presentan los temas; Desarrollo, en el que el compositor amplía, varía y contrasta esos temas; y Reexposición, en la que se retoma toda o parte de la Exposición. La estructura que acabamos de ver, la «forma-sonata», ocupa generalmente el primer movimiento de las sinfonías, conciertos, oberturas, etc.

En sentido lato, precisamente, se llama sonata a una obra completa de tres o cuatro movimientos, como, por ejemplo, una sinfonía, concierto, etc. El primer movimiento, el más fijo, viene dado, como ya dijimos, por la «forma-sonata», o sea,

${ }^{20}$ Mikel Dufrenne, op., cit., tomo I, pp. 310 y 313. 
que este primer movimiento consta de Exposición, Desarrollo y Reexposición, los cuales constituyen el allegro inicial. El segundo movimiento puede llevar también la «forma-sonata», aunque son usuales el tipo lied, rondó o la estructura de tema con variaciones. Este segundo movimiento es normalmente lento. Al tercer movimiento le corresponden las rítimicas formas de Minué o de Scherzo. El cuarto movimiento (allegro final) suele retomar la «forma-sonata» del primer movimiento (allegro inicial).

Con respecto a algunas obras de Carpentier (vg. El acoso), la crítica no se ha puesto de acuerdo sobre qué significa, en realidad, «sonata» para el novelista, puesto que el término puede ser interpretado en cualquiera de los dos sentidos arriba explicados. Sin embargo, es necesario observar que, en cualquiera de los dos sentidos, la sonata es una estructura perfectamente cerrada, que hacia el final retoma el principio variándolo. El siglo de las luces admite las dos acepciones de «sonata».

Se ajusta la novela al concepto propiamente técnico. La Exposición vendría dada por el capítulo I. Allí se plantean los tres temas esenciales: un tema mayor o masculino (Víctor), un tema menor, afectivamente complejo (Esteban) y un tema femenino (Sofía). También se exponen, claro es, casi todos los demás motivos que, en el desarrollo, sufrirán diversas matizaciones y variaciones: nuevas ideas, trajes, aldaba, etc.

El Desarrollo se dilataría desde el capítulo II hasta el VI, ambos incluidos. Asistimos aquí a las evoluciones contrapuntísticas Esteban-Víctor, Sofía-Víctor y Esteban-Sofía. Al mismo tiempo se producen las variaciones sobre la multitud de motivos recurrentes. Se apuntala la estructrura de la obra, impidiendo a la vez que la duración se devanezca. La evolución de los motivos es paralela al sentido o movimiento general de la obra. Por ejemplo, el aldabonzado inicial en la casa de La Habana, trasposición sonora del afán de Víctor de imponer convicciones, es visto al principio por los jóvenes como una intromisión en el espacio cerrado de la adolescencia. Luego, siguiendo el curso de la obra, evoluciona hacia entonaciones positivas, coincidiendo con el deseo de acción de los protagonistas. Tras el fracaso de Esteban con Víctor, el motivo de la aldaba vuelve a teñirse de negatividad, ya que Esteban intenta, sin conseguirlo, reconstruir el idilio inicial, por lo que la aldaba golpeada vuelve a considerarse como intromisión -ahora a causa de los muchos resabios del joven-. Sin embargo, para Sofía, que inicia en ese momento su aventura revolucionaria, el aldabonazo será todavía la llamada hacia una esperanza, hasta que se produzca el fracaso definitivo.

La Reexposición estaría constituida por el último capítulo. De algún modo, este capítulo VII es la conclusión de todo el proceso anterior. La muerte de los jóvenes es la heroica sublimación de tantas experiencias revolucionarias fracasadas. Pero este capítulo también supone una recuperación del inicial. Ya hemos analizado antes los indicios que permiten suponer que Sofía y Esteban se desenvolvían en la casa de Madrid en un ambiente muy similar -aunque no «idéntico»- al de la casa de La Habana, ambiente cerrado que en los dos casos se abre hacia sendas revoluciones, una fracasada, redimida la otra.

Pasemos ahora a la segunda acepción del término. La obra se ajusta igualmente al sentido lato de sonata y, en este caso, El siglo de las luces se asemejaría más bien 
a una larga sinfonía, cuyos movimientos primeros y cuarto contendrían la estructura técnica de la «forma-sonata» (Exposición, Desarrollo y Reexposición). El allegro inicial sería el capítulo I. Se exponen los tres temas protagonistas y la virtualidad de cada cual. Se desarrollan rápidamente los diversos cambios ocurridos, y se concluye con la salida para la acción de Esteban y Víctor.

El movimiento lento (o andante) vendría dado por los capítulos II, III y IV, sirviendo el V como enlace o transición hacia el tercer movimiento. Se desarrolla aquí detenidamente el contrapunto Esteban-Víctor, siguiéndose paso a paso las pugnas entre idealismo inoperante y política. Esteban pasa de su estado fetal a la apertura, para después, desengañado, intentar volver al estado idílico, lo que se evidencia a las claras en el capítulo de enlace (V). Víctor pasa de comerciante (la prueba de fuego sería el incendio de su panadería en Port-au-Prince) a investido de poderes. Después, paulatinamente, recobra su estampa burguesa hasta desembocar en la franca contrarrevolución, en el tiempo de Sísifo. La relación entre ambos ev oluciona desde la armonía inicial hasta la ruptura de los nexos, pasando por agudas tensiones. Amén de la sólida red que conforman los motivos recurrentes, contribuyen al movimiento lento las largas descripciones del Caribe y del infierno de Cayena, donde la naturaleza adquiere papel protagonista. Esteban se siente preso en el tiempo detenido, infructuoso, y ve como símbolo la epopeya trunca de los caribes.

Al tercer movimiento, Sherzo o Minué, corresponde el capítulo VI. El contrapunto Sofía-Víctor, ya lo hemos indicado, es una variación breve y rítmica de la relación Esteban-Víctor. Sofía no asiste paso a paso a la quiebra del francés. La aventura se inicia con los mismos anhelos, se desarrolla en forma de tensión y concluye con la ruptura de los nexos, cerrándose el ciclo de la enajenación. La variación esencial estriba en que Sofía no sucumbe a los resabios, sabe mantener la esperanza y no desea volver a la casa de La Habana. El contrapunto Sofía-Víctor es mucho más rápido que el anterior. No se focaliza la evolución del agente. La mujer se encuentra ya ante un hombre fracasado moralmente, aunque -para hacer más evidente el paralelismo estructural- Víctor haya sido nuevamente investido de poderes en Cayena. Pero este poder, en cuanto está fundado en la acomodación burguesa a la reacción thermidoriana, es injustificable -forma vacía, tiempo muerto-. Más que a un lento desarrollo, asistimos a una rápida sucesión de irónicos y decepcionantes encontronazos entre la mujer y el agente. Baste recordadr la barahúnda porcina, la pinta de parricida de Víctor y lo hueco de su traje de comisario abandonado en una silla de tapicería deshilachada.

El capítulo VII constituye el allegro final, el más corto de todos y el que retoma el allegro inicial. Sofía y Esteban recuperan un ámbito semejante al de la adolescencia, ámbito que también resulta quebrantado, pero ahora por una revolución espóntanea y que no se deshace en contradicciones. Las breves encuestas efectuadas por Carlos para saber de sus familiares contribuyen al movimiento de allegro. La muerte realiza a los jóvenes. Ya no preside una voluntad ajena, sino la propia -sobre todo en el caso de Sofía-. «Las palabras no caen en el vacío» es la sugerente conclusión de esta perfecta sonata de Carpentier. 
